\title{
Intratumoral and peritumoral expression of CD68 and CD206 in hepatocellular carcinoma and their prognostic value
}

\author{
CHUN-XIA REN ${ }^{1-3}$, RUI-XUE LENG ${ }^{1,2}$, YIN-GUANG FAN ${ }^{1,2}$, HAI-FENG PAN $^{1,2}$, BAO-ZHU LI $^{1,2}$, \\ CHANG-HAO WU ${ }^{4}$, QIANG WU ${ }^{5}$, NA-NA WANG ${ }^{5}$, QI-RU XIONG ${ }^{3}$, XIAO-PING GENG ${ }^{3}$ and DONG-QING YE ${ }^{1,2}$ \\ ${ }^{1}$ Department of Epidemiology and Biostatistics, School of Public Health, and ${ }^{2}$ Anhui Province Key Laboratory \\ of Major Autoimmune Diseases, Anhui Medical University; ${ }^{3}$ General Department of Surgery, The First Affiliated Hospital \\ of Anhui Medical University, Hefei, Anhui, P.R. China; ${ }^{4}$ Faculty of Health and Medical Sciences, University of Surrey, \\ Guildford, Surrey, UK; ${ }^{5}$ Pathology Center, Department of Pathology, Anhui Medical University, Hefei, Anhui, P.R. China
}

Received January 14, 2017; Accepted June 7, 2017

DOI: $10.3892 /$ or.2017.5738

\begin{abstract}
The aims of the present study were to determine whether the changes in density and location of CD68-positive and CD206-positive macrophages contribute to progression of hepatocellular carcinoma (HCC) and to evaluate prognostic values of these cells in post-surgical patients. A retrospective study involving $268 \mathrm{HCC}$ patients was conducted. CD68-positive and CD206-positive macrophage infiltration in HCC tissues and adjacent tissues was examined by immunohistochemistry (IHC) and the relationship between the clinicopathological features and prognosis was analyzed. Receiver operating characteristics (ROC) curve was used to calculate diagnostic accuracy. There was an increase in CD68-positive and CD206-positive macrophage infiltration in adjacent tumor tissues compared with tumor tissues. ROC curve identified their optimal diagnostic cut-off values. The survival analysis showed that increased CD68 expression in adjacent tissues conferred superior overall survival (OS) and disease-free survival (DFS), while increase of CD206 in tumor yielded inferior OS and DFS. Cox regression analysis suggested both CD68-positive macrophages in adjacent area and intratumor CD206-positive macrophages as independent prognostic biomarkers for post-surgical HCC patients. Finally,
\end{abstract}

Correspondence to: Dr Dong-Qing Ye, Department of Epidemiology and Biostatistics, School of Public Health, Anhui Medical University, Meishan Road 81, Hefei, Anhui 230022, P.R. China

E-mail: ydq@ahmu.edu.cn; ydqahmu@gmail.com

*Contributed equally

Abbreviations: HCC, hepatocellular carcinoma; TAMs, tumorassociated macrophages; IHC, immunohistochemistry; ROC, receiver operating characteristics; OS, overall survival; DFS, disease-free survival; AUC, area under curve; M1, classically activated macrophages; M2, alternatively activated macrophages, TNM, tumor-node-metastasis

Key words: hepatocellular carcinoma, tumor-associated macrophages, CD68, CD206, prognosis a combination of CD68/CD206 and HBV-positive further improved prognostic stratification, especially in DFS. These results provide the first evidence for region- and subsetdependent involvement of CD68 and CD206 cells in HCC progression. A combination of CD68/CD206 density and HBV-positivity improves further predictive value for postoperative recurrence of HCC. Quantification of CD68/CD206 macrophages and their distribution can be exploited for better postsurgical management of HCC patients. These findings provide a basis for developing novel treatment strategies aimed at re-educating macrophages in tumor microenvironment.

\section{Introduction}

Hepatocellular carcinoma (HCC) is one of the most lethal malignancies ranking as the fifth most common cancer worldwide (1). The incidence of advanced HCC cases who underwent multiple metastasis and dismal prognosis is increasing and usually the lack of effective treatment options will lead to serious social burdens (2). Currently, radical or partial hepatectomy represents the standard of care for patients with early diagnosis. However, distant metastases and postoperative relapse remain tremendous challenges. Therefore, identification of potential new therapeutic targets and prognostic biomarkers would be of great benefit to HCC patients.

Recent advance suggests that inflammation plays a critical role in carcinogenesis. As pivotal mediators in the inflammatory response, macrophages could generally be polarized into two principal subtypes: classically activated macrophages (M1) and alternatively activated macrophages (M2) (3). However, the two classes of macrophages play a diverse role in exhibiting pro- and anti-inflammatory activities, respectively. Tumor-associated macrophages (TAMs) are recruited to tumors by various cytokines and growth factors (4). They are widely documented as a fundamental cellular component within the tumor immune microenvironment, even having distinct phenotypes of TAMs at different stages of the tumor (5). TAMs substantially affect the fate of cancer cells and the clinical outcome by interacting in a complicated manner with neoplastic cells $(6,7)$. Generally, TAMs 
are of M2-like phenotype and have a protumor role. This is supported by the evidence that these macrophages can promote tumor progression and metastasis by orchestrating tumor cell motility, invasion, angiogenesis and antitumor immunity $(8,9)$. In majority of solid tumors, TAMs were often associated with decreased patient survival (10-12). Nonetheless, conflicting results have been observed by several investigators in some types of cancers, for example, non-small cell lung cancer and papillary renal cell carcinoma $(13,14)$.

CD68 is commonly considered to be a pan-macrophage marker $(15,16)$. However, CD68 cannot distinguish M1 or M2 subtype from all the pan-macrophages (15). In addition to its existence in resident macrophages of multiple tissues, CD68 is also expressed in tumor-infiltrating macrophages. CD206 is known to be expressed on the surface of most classes of macrophages and dendritic cell subpopulations, and is routinely used to identify the M2 phenotype (17). CD206 is involved in antigen presentation, endocytosis and phagocytosis, signal transduction, innate host defense and the adaptive immune response (18). To date, both CD68 and CD206 have been the subjects of extensive structural and functional investigation in human diseases, especially in tumors. The associations of CD68-positive or CD206-positive macrophages with poor prognosis have been extensively documented in various types of malignancies, such as oral squamous cell carcinoma, breast cancer and HCC (19-24). However, the clinical relevance of macrophages infiltration to distinct histologic locations to HCC prognosis remained unclear. A better understanding of the roles of CD68 and CD206 macrophages in HCC may provide valuable information for prevention and treatment of HCC. Herein, we initiated a comparative follow-up study to explore their distribution and expression, as well as prognostic value in primary $\mathrm{HCC}$.

\section{Materials and methods}

Patients and specimens. A total of 268 anonymized patients with primary HCC were collected and pathologically confirmed by Pathology Department of the First Affiliated Hospital of Anhui Medical University were enrolled in the present study. All the patients aged $>18$ years underwent surgical curative resection with follow-up from October 2011 to December 2016. Concurrence of other malignant diseases, autoimmune disease, syphilis and human immunodeficiency virus were excluded from the study. None of the cases received chemotherapy and/or radiotherapy previous to surgery. Total of 266 primary tumor tissues were grouped into case subjects and 243 tumor adjacent tissues were evaluated as the control group. Paired, formalin-fixed and paraffin-embedded (FFPE) primary tumor tissues and tumor adjacent tissues specimens were obtained from the whole patient population. This study was approved by the Human Research Ethics Committee of Anhui Medical University. Informed consents were obtained from all the participating patients.

In the present study, the hematoxylin and eosin slides were independently examined, and the histological diagnoses were re-evaluated systematically by two experienced pathologists who were blinded to the clinical outcome of the samples based on WHO classifications of HCC. Clinical stages of tumor progression were determined according to the tumor-node-metastasis (TNM) classification system of the International Union against Cancer/American Joint Committee on Cancer (IUAC/AJCC) (Edition 7). The following clinical data were obtained in a well-designed questionnaire, including TNM stage, demographics (sex and age), family history, alcohol consumption, laboratory data including alpha fetoprotein (AFP), serum albumin and total bilirubin (TBIL).

Reagents. The following primary antibodies were used: mouse anti-CD68 antibody (KP1) (cat. no. ab845), mouse anti-CD206 antibody (cat. no. ab117644) and they were obtained from Abcam (Cambridge, MA, USA). Anti-CD68 antibody was prediluted. The anti-CD206 antibody was applied at a dilution of 1:200. Both immunohistochemical MaxVision kit and diaminobenzidine (DAB) chromogenic reagent kit were purchased from Fuzhou Maixin Biotech, Co., Ltd. (Fuzhou, China).

Immunohistochemistry. We detected the expression of CD206 and CD68 in two different areas with IHC staining and further calculated their distribution densities. FFPE tissue sections ( $4 \mu \mathrm{m}$-thick) were processed for IHC staining with mouse anti-human CD68 antibody and mouse anti-human CD206 antibody as described. IHC assay was performed with MaxVision IHC kit and DAB chromogenic reagent kit. Briefly, the protocol was as described below. First, the tissue sections were deparaffinized and hydrated, immersed in ethylene diamine tetraacetic acid buffer ( $\mathrm{PH} \mathrm{8.0)} \mathrm{and} \mathrm{heated}$ for $15 \mathrm{~min}$ in a microwave oven for antigen retrieval. Next, the primary antibody against CD68 or CD206 was added to the specimen sections at $4^{\circ} \mathrm{C}$ and incubated overnight, which were then developed using the immunohistochemical MaxVision kit. The primary antibody was removed, and the secondary antibody was incubated with the samples $(1: 1,000)$ at $37^{\circ} \mathrm{C}$ for $30 \mathrm{~min}$. The kit solution was incubated with tissue samples at room temperature for $20 \mathrm{~min}$, and thereafter, DAB chromogenic reagent was added. Finally, hematoxylin staining was carried out. The primary antibody was replaced with phosphate buffered saline, which was used as the negative control. IHC staining of positive samples was repeated twice.

Counting. The tan or brown granules in the cytoplasm of cancer or adjacent cancer macrophages observed in the IHC assay were considered positive staining. Quantitative analysis of CD68 and CD206 in the stained sections was independently performed by two pathologists blinded to the clinical data. The mean score of five high-power fields (HPF) $(\times 400)$ was counted for each slide by an optical microscope of Leica (DM2500; Leica Microsystems, Wetzlar, Germany).

Follow up study. Follow-up evaluations were performed every 3 months for the first year and annually thereafter for locally advanced tumor stages. Among all the 268 patients, 199 patients who completed the follow-up were further enrolled in survival analysis (69 cases were dropped). The scores of CD68-positive and CD206-positive were compared with demographical, clinical and histopathological characteristics. All these variables were tested as predictors of patient's OS and DFS. OS was defined as the interval between the dates 
of surgery and death or the last follow-up. DFS was defined as the interval between the dates of surgery and the first recurrence or the latest date of follow-up.

Statistical analysis. Statistical Package for Social Sciences version 16.0 (SPSS 16.0; SPSS Inc., Chicago, IL, USA), MedCalc version 11.4.2.0 (MedCalc Software, Mariakerke, Belgium) and Graphpad Prism version 5.0 (Graphpad Software, Inc., La Jolla, CA, USA) were used in the present study. Quantitative variables following a normal distribution were presented as mean \pm standard deviation (SD), and the difference between/among groups were tested using t-test or one-way ANOVA. Quantitative variables with a skewed distribution were presented as medians with interquartile ranges (IQRs), and the differences between/among groups were tested using Mann-Whitney U test and Kruskal-Wallis test. Correlations of CD68/CD206-positive macrophages between the intratumor and the tumor adjacent tissue or between the two types of infiltrated macrophages were tested using the non-parametric Spearman's rank analysis. Then, the receiver operating characteristics (ROC) curve analysis was plotted to calculate the diagnostic accuracy of CD68 and CD206. The optimum cut-off value for diagnosis was determined by maximizing the sum of sensitivity and specificity. In addition, Kaplan-Meier survival curves and log-rank test were used to analyze the correlations between the CD68-positive and the CD206-positive macrophage numbers and survival of postsurgical HCC patients. Finally, Cox proportional hazards regression was employed for univariate and multivariate analysis of OS and DFS. Differences were considered statistically significant at two-sided $\mathrm{P}<0.05$.

\section{Results}

The clinicopathological characteristics of HCC patients. This study comprised 268 patients with HCC and their clinicopathological parameters are given in Table I. The majority of cases were male $(229,85.4 \%)$ and nearly $50 \%$ of cases were aged under 54 years. Among the cases, near 80\% (209, 78\%) had positive HBV and nearly half $(112,41.8 \%)$ HCC cases presented liver cirrhosis. Of these patients, 264 (98.51\%) were considered early stage HCC: Child-Pugh-A ( $\mathrm{n}=238,88.8 \%)$, Child-Pugh-B $(n=26,9.7 \%)$ and Child-Pugh-C $(n=4,1.5 \%)$.

Distribution of CD68 and CD206 in HCC tissues and adjacent area. Liver histology results for CD68-positive and CD206-positive macrophages are depicted in Fig. 1. Among all specimens in our studies, CD68 expression was specific to macrophages and was shown in cell membrane and cytoplasm in brown color. Furthermore, the cells positively stained for CD206 often displayed typical macrophage morphology. CD68-positive and CD206-positive macrophages were infiltrated in both primary tumor tissues (Fig. 1A and C) and tumor adjacent tissues (Fig. 1B and D). However, the adjacent tissue was infiltrated with higher density of both CD68-positive and CD206-positive macrophages compared with intratumor compartments $(\mathrm{P}<0.001$ and $\mathrm{P}<0.001$, respectively). The average levels of CD68 and CD206 staining are shown in Table IV. Additionally, in tumor adjacent tissues, the density of infiltrated CD68-positive macrophages was much higher than
Table I. Clinicopathological characteristics of HCC patients.

\begin{tabular}{lr}
\hline Clinical variables & $\mathrm{n}(\%)$ \\
\hline Sex & \\
Male & $229(85.4)$ \\
Female & $39(14.6)$ \\
Age (years) & \\
$<54$ & $133(49.6)$ \\
$\geq 54$ & $135(50.4)$ \\
Alcohol intake & \\
Yes & $95(35.4)$ \\
No & $173(64.6)$ \\
HBV & \\
Positive & $209(78.0)$ \\
Negative & $59(22.0)$ \\
Liver cirrhosis & \\
Present & $112(41.8)$ \\
Absent & $156(58.2)$ \\
PHT & \\
Present & $19(7.1)$ \\
Absent & $249(92.9)$ \\
TBIL $(\mu$ mol/l) & \\
$<34$ & $257(95.9)$ \\
$\geq 34$ & \\
NG & \\
A P $(n .0)$
\end{tabular}

$\operatorname{AFP}(\mathrm{ng} / \mathrm{ml})$

$<400$

$161(60.1)$

$\geq 400$

$107(39.9)$

Child-Pugh class

A

$238(88.8)$

B

$26(9.7)$

C

$4(1.5)$

Tumor size $(\mathrm{cm})$

$<5$

$130(48.5)$

$\geq 5$

$138(51.5)$

Lymph node metastasis

Present

Absent

$253(94.4)$

NG

$11(4.1)$

TNM stage

I + II

$203(75.8)$

$\mathrm{III}+\mathrm{IV}$

Degree of histologic differentiation

$\begin{array}{lc}\text { High } & 28(10.5) \\ \text { Moderate } & 111(41.4) \\ \text { Low } & 104(38.8) \\ \text { NG } & 25(9.3)\end{array}$

HBV, hepatitis B virus; PHT, portal hypertension; TBIL, total bilirubin; AFP, alpha-fetoprotein; TNM, tumor-node-metastasis; NG, not get. 


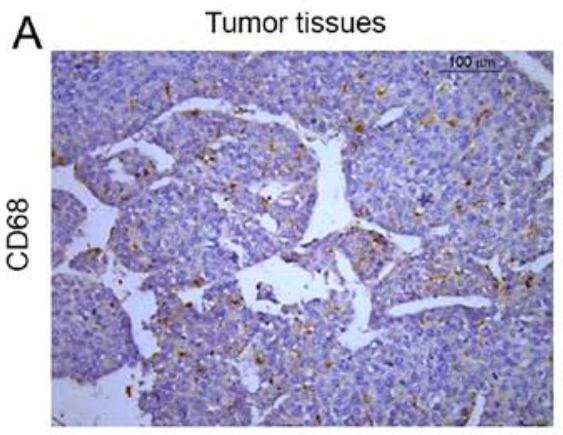

B
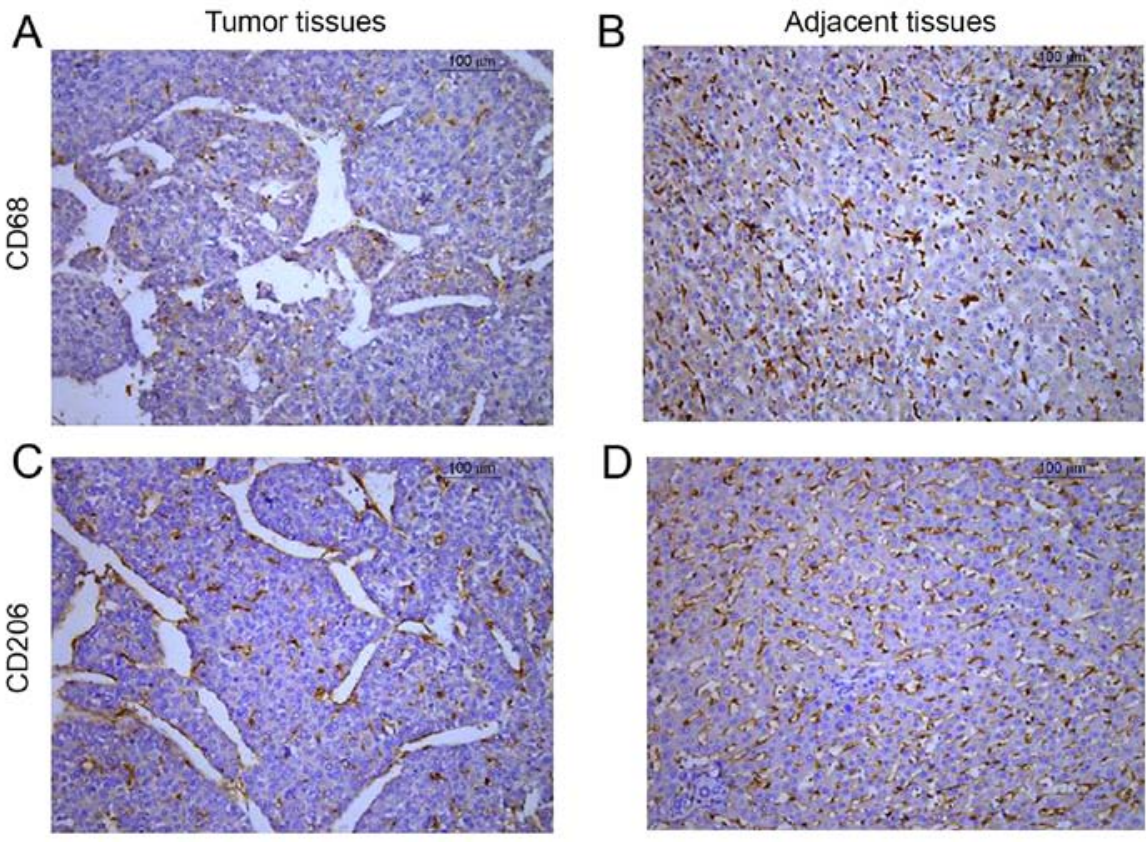

Figure 1. CD68-positive and CD206-positive macrophages in HCC tissues and adjacent tissues. Immunoreactivity to anti-CD68 (A and B) and anti-CD206 $(\mathrm{C}$ and $\mathrm{D})$ in tumor tissues (A and C) and adjacent tissues (B and D) of HCC.
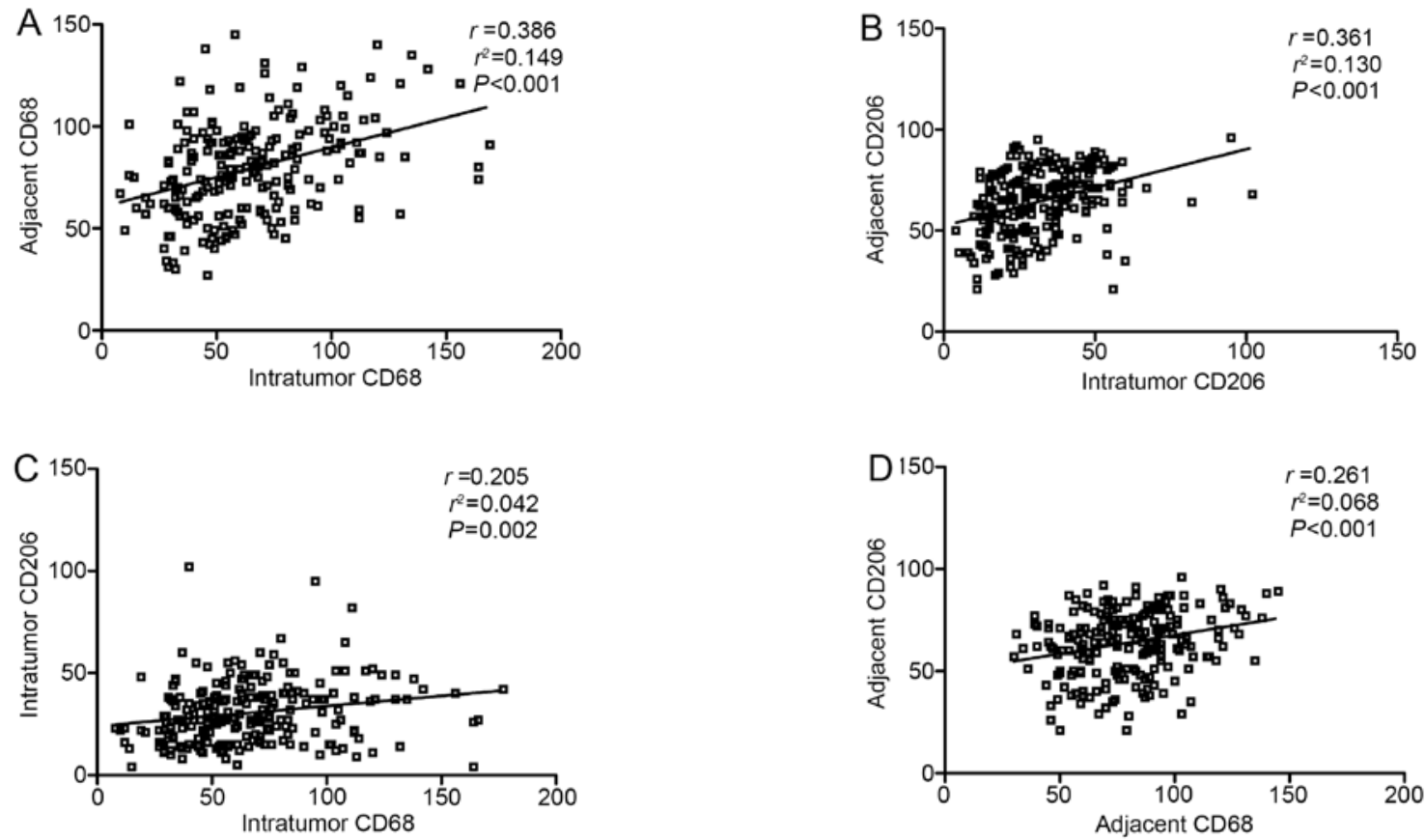

Figure 2. Correlation between infiltrated CD68-positive and CD206-positive macrophages in different areas of HCC. (A) CD68 expression between intratumor tissues and adjacent tissues ( $\mathrm{r}=0.392 ; \mathrm{P}<0.001)$. (B) CD206 expression in intratumor tissues and adjacent tissues $(\mathrm{r}=0.360 ; \mathrm{P}<0.001)$. (C) Positive correlation between CD206 and CD68 in intratumor tissues ( $r=0.237 ; \mathrm{P}<0.001)$. (D) Positive correlation between CD206 and CD68 in adjacent tissues $(r=0.261 ; \mathrm{P}<0.001)$.

that of CD206-positive macrophages $(\mathrm{P}<0.001)$ and the same pattern can be seen in the intratumor area $(\mathrm{P}<0.001)$.

Spearman's rank correlation coefficient analysis revealed a significant correlation in CD68 density between the intratumor tissues and the adjacent compartments ( $\mathrm{r}=0.392$; $\mathrm{P}<0.001$; Fig. 2A). Similar results were obtained in the CD206-positive macrophages ( $\mathrm{r}=0.360$; $\mathrm{P}<0.001$; Fig. $2 \mathrm{~B}$ ). This suggests a functional link between the intratumor macrophages and the adjacent macrophages. Notably, CD206 expression was positively correlated with CD68 expression in both intratumor tissues ( $\mathrm{r}=0.237$; $\mathrm{P}<0.001$; Fig. $2 \mathrm{C}$ ) and adjacent tissues $(\mathrm{r}=0.261$; $\mathrm{P}<0.001$; Fig. 2D) from $\mathrm{HCC}$ patients. It may imply some interaction between CD68 and CD206 cells.

Correlation of CD68/CD206 density with clinical characteristics. The relationship between the expression of CD68 and CD206 in HCC and the clinicopathological 
Table II. Correlation of CD68-positive expression with clinicopathological characteristics of HCC patients.

\begin{tabular}{|c|c|c|c|c|c|c|}
\hline \multirow[b]{2}{*}{ Clinical variables } & \multicolumn{3}{|c|}{ Intratumor CD68 } & \multicolumn{3}{|c|}{ Adjacent CD68 } \\
\hline & $\mathrm{n}$ & Mean \pm SD & P-value & $\mathrm{n}$ & Mean \pm SD & P-value \\
\hline Sex & & & 0.125 & & & 0.142 \\
\hline Male & 190 & $65.42 \pm 32.11$ & & 206 & $77.62 \pm 23.04$ & \\
\hline Female & 35 & $74.71 \pm 36.18$ & & 37 & $83.62 \pm 21.47$ & \\
\hline Age (years) & & & 0.027 & & & 0.893 \\
\hline$<54$ & 106 & $61.86 \pm 27.53$ & & 117 & $78.45 \pm 22.66$ & \\
\hline$\geq 54$ & 118 & $71.42 \pm 36.66$ & & 125 & $78.85 \pm 23.10$ & \\
\hline Alcohol intake & & & 0.901 & & & 0.258 \\
\hline Yes & 79 & $66.49 \pm 30.13$ & & 83 & $80.84 \pm 24.52$ & \\
\hline No & 146 & $67.07 \pm 34.36$ & & 160 & $77.34 \pm 21.95$ & \\
\hline HBV & & & 0.954 & & & 0.030 \\
\hline Positive & 171 & $66.80 \pm 32.99$ & & 188 & $76.81 \pm 21.90$ & \\
\hline Negative & 54 & $67.09 \pm 32.77$ & & 55 & $84.42 \pm 25.26$ & \\
\hline Liver cirrhosis & & & 0.633 & & & 0.946 \\
\hline Present & 91 & $65.59 \pm 34.68$ & & 103 & $78.65 \pm 22.68$ & \\
\hline Absent & 134 & $67.73 \pm 31.68$ & & 140 & $78.45 \pm 23.09$ & \\
\hline PHT & & & 0.043 & & & 0.050 \\
\hline Present & 19 & $52.26 \pm 21.37$ & & 18 & $68.39 \pm 18.48$ & \\
\hline Absent & 206 & $68.21 \pm 33.45$ & & 225 & $79.35 \pm 23.03$ & \\
\hline TBIL & & & 0.258 & & & 0.202 \\
\hline$<34$ & 214 & $67.36 \pm 32.30$ & & 232 & $78.81 \pm 23.01$ & \\
\hline$\geq 34$ & 8 & $53.88 \pm 50.26$ & & 8 & $68.25 \pm 20.77$ & \\
\hline $\mathrm{AFP}(\mathrm{ng} / \mathrm{ml})$ & & & 0.008 & & & 0.026 \\
\hline$<400$ & 133 & $62.03 \pm 30.84$ & & 146 & $75.88 \pm 23.18$ & \\
\hline$\geq 400$ & 92 & $73.86 \pm 34.59$ & & 97 & $82.54 \pm 21.91$ & \\
\hline Child-Pugh class & & & 0.470 & & & 0.209 \\
\hline A & 197 & $67.60 \pm 32.73$ & & 215 & $79.20 \pm 22.82$ & \\
\hline $\mathrm{B}$ & 24 & $63.83 \pm 36.34$ & & 24 & $71.21 \pm 22.82$ & \\
\hline $\mathrm{C}$ & 4 & $48.75 \pm 4.43$ & & 4 & $86.50 \pm 22.25$ & \\
\hline Tumor size $(\mathrm{cm})$ & & & 0.072 & & & 0.012 \\
\hline$<5$ & 103 & $62.74 \pm 33.33$ & & 107 & $75.57 \pm 21.46$ & \\
\hline$\geq 5$ & 115 & $70.66 \pm 31.21$ & & 127 & $83.00 \pm 23.34$ & \\
\hline Lymph node metastasis & & & 0.654 & & & 0.523 \\
\hline Present & 8 & $72.00 \pm 26.67$ & & 8 & $83.63 \pm 12.31$ & \\
\hline Absent & 217 & $66.68 \pm 33.11$ & & 235 & $78.36 \pm 23.14$ & \\
\hline TNM stage & & & 0.143 & & & 0.491 \\
\hline $\mathrm{I}+\mathrm{II}$ & 168 & $64.99 \pm 33.84$ & & 185 & $77.97 \pm 23.37$ & \\
\hline $\mathrm{III}+\mathrm{IV}$ & 57 & $72.39 \pm 29.40$ & & 58 & $80.34 \pm 21.29$ & \\
\hline Tumor differentiation & & & 0.767 & & & 0.283 \\
\hline Well & 26 & $62.88 \pm 38.15$ & & 27 & $84.74 \pm 18.60$ & \\
\hline Moderate & 88 & $68.13 \pm 29.20$ & & 99 & $77.00 \pm 21.79$ & \\
\hline Poor & 91 & $67.21 \pm 33.43$ & & 94 & $79.01 \pm 24.02$ & \\
\hline
\end{tabular}

SD, standard deviation; HBV, hepatitis B virus; PHT, portal hypertension; TBIL, total bilirubin; AFP, alpha-fetoprotein; TNM, tumor-nodemetastasis.

features is listed in Tables II and III. We noted that a higher CD68 density was found in the older patients intratumorally
$(\mathrm{P}=0.027)$. Cases with portal hypertension (PHT) appeared to have lower intratumor CD68 expression compared with 
Table III. Correlation of CD206-positive expression with clinicopathological characteristics of HCC patients.

\begin{tabular}{|c|c|c|c|c|c|c|}
\hline \multirow[b]{2}{*}{ Clinical variables } & \multicolumn{3}{|c|}{ Intratumor CD206 } & \multicolumn{3}{|c|}{ Adjacent CD206 } \\
\hline & $\mathrm{n}$ & Mean \pm SD & P-value & $\mathrm{n}$ & Mean \pm SD & P-value \\
\hline Sex & & & 0.013 & & & 0.297 \\
\hline Male & 227 & $30.50 \pm 14.47$ & & 202 & $77.62 \pm 23.04$ & \\
\hline Female & 39 & $37.03 \pm 17.75$ & & 35 & $83.62 \pm 21.47$ & \\
\hline Age (years) & & & 0.828 & & & 0.185 \\
\hline$<54$ & 131 & $31.73 \pm 14.42$ & & 118 & $65.83 \pm 16.35$ & \\
\hline$\geq 54$ & 134 & $31.32 \pm 15.84$ & & 118 & $63.10 \pm 15.18$ & \\
\hline Alcohol intake & & & 0.574 & & & 0.813 \\
\hline Yes & 93 & $32.14 \pm 13.76$ & & 84 & $64.73 \pm 15.67$ & \\
\hline No & 173 & $31.09 \pm 15.85$ & & 153 & $64.22 \pm 15.93$ & \\
\hline HBV & & & 0.375 & & & 0.365 \\
\hline Positive & 208 & $31.02 \pm 14.84$ & & 183 & $63.89 \pm 15.88$ & \\
\hline Negative & 58 & $33.02 \pm 16.21$ & & 54 & $66.11 \pm 15.56$ & \\
\hline Liver cirrhosis & & & 0.177 & & & 0.035 \\
\hline Present & 111 & $29.97 \pm 13.35$ & & 98 & $61.82 \pm 16.22$ & \\
\hline Absent & 155 & $32.52 \pm 16.25$ & & 139 & $66.22 \pm 15.30$ & \\
\hline PHT & & & 0.971 & & & 0.240 \\
\hline Present & 19 & $31.58 \pm 10.89$ & & 13 & $59.38 \pm 18.38$ & \\
\hline Absent & 247 & $31.45 \pm 15.43$ & & 224 & $64.69 \pm 15.64$ & \\
\hline TBIL & & & 0.349 & & & 0.007 \\
\hline$<34$ & 255 & $31.15 \pm 15.19$ & & 228 & $64.74 \pm 15.61$ & \\
\hline$\geq 34$ & 8 & $36.25 \pm 13.51$ & & 6 & $47.00 \pm 16.86$ & \\
\hline $\mathrm{AFP}(\mathrm{ng} / \mathrm{ml})$ & & & 0.486 & & & 0.338 \\
\hline$<400$ & 161 & $30.93 \pm 14.95$ & & 143 & $65.20 \pm 15.05$ & \\
\hline$\geq 400$ & 105 & $32.26 \pm 15.45$ & & 94 & $63.18 \pm 16.89$ & \\
\hline Child-Pugh class & & & 0.001 & & & 0.240 \\
\hline A & 236 & $31.01 \pm 14.63$ & & 213 & $64.96 \pm 15.63$ & \\
\hline $\mathrm{B}$ & 26 & $31.27 \pm 13.22$ & & 21 & $58.86 \pm 15.86$ & \\
\hline $\mathrm{C}$ & 4 & $59.00 \pm 31.52$ & & 3 & $63.33 \pm 26.31$ & \\
\hline Tumor size $(\mathrm{cm})$ & & & 0.886 & & & 0.385 \\
\hline$<5$ & 129 & $31.32 \pm 15.14$ & & 113 & $63.46 \pm 14.92$ & \\
\hline$\geq 5$ & 137 & $31.58 \pm 15.18$ & & 124 & $65.25 \pm 16.59$ & \\
\hline Lymph node metastasis & & & 0.734 & & & 0.859 \\
\hline Present & 8 & $33.25 \pm 27.73$ & & 8 & $65.38 \pm 18.90$ & \\
\hline Absent & 258 & $31.40 \pm 14.67$ & & 229 & $64.36 \pm 15.73$ & \\
\hline TNM stage & & & 0.357 & & & 0.013 \\
\hline $\mathrm{I}+\mathrm{II}$ & 201 & $30.96 \pm 14.97$ & & 181 & $62.99 \pm 15.88$ & \\
\hline III + IV & 65 & $33.00 \pm 15.65$ & & 56 & $68.95 \pm 14.78$ & \\
\hline Tumor differentiation & & & 0.445 & & & 0.644 \\
\hline Well & 28 & $28.07 \pm 10.65$ & & 24 & $66.08 \pm 13.39$ & \\
\hline Moderate & 111 & $31.72 \pm 13.47$ & & 99 & $65.07 \pm 15.34$ & \\
\hline Poor & 102 & $32.00 \pm 17.07$ & & 92 & $63.29 \pm 17.22$ & \\
\hline
\end{tabular}

SD, standard deviation; HBV, hepatitis B virus; PHT, portal hypertension; TBIL, total bilirubin; AFP, alpha-fetoprotein; TNM, tumor-nodemetastasis.

those without PHT $(\mathrm{P}=0.043)$, but the difference in adjacent tumor data did not reach a statistical significance $(\mathrm{P}=0.050)$. Patients whose AFP concentration was $>400 \mathrm{ng} / \mathrm{ml}$ might have much higher density of CD68 TAMs in both primary tumor tissues and tumor adjacent tissues $(\mathrm{P}=0.008$ and $\mathrm{P}=0.026$, respectively). Patients with high expression of CD68 in tumor adjacent tissue were prone to have a larger tumor size $(\mathrm{P}=0.012)$. As for $\mathrm{CD} 206$, its density in adjacent tissue 


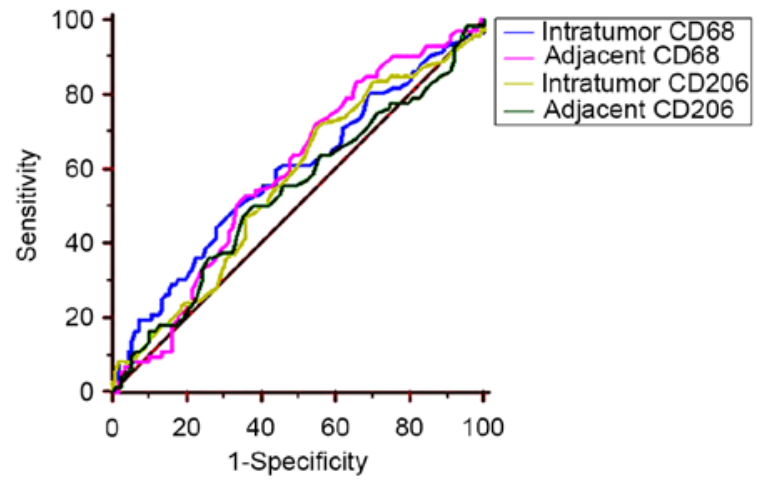

Figure 3. The optimal diagnostic cut-off for intratumor CD68 was 71/hpf and 87/hpf for adjacent tumoral CD68 in the diagnosis of HCC.

was significantly higher in patients with cirrhosis $(\mathrm{P}=0.035)$ or poor TNM stages $(\mathrm{P}=0.013)$. The HCC cases with younger age or better Child-Pugh class had lower intratumor CD206 expression $(\mathrm{P}=0.001)$. Individuals with higher level of TBIL possessed decreased expression of $\mathrm{CD} 206(\mathrm{P}=0.007)$ in tumor adjacent tissue. However, no statistical significance was observed in the expression of CD68 and CD206 with tumor differentiation, lymph node metastasis and alcohol intake.

Diagnostic prediction of CD68/CD206 staining for HCC. AFP is a valuable serological biomarker. A level $>400 \mathrm{ng} / \mathrm{ml}$ was defined as cut-off value to evaluate sensitivity and specificity of CD68 and CD206. ROC curves showed that the optimal diagnostic cut-off for intratumor CD68 was 71/HPF [area under curve (AUC) $0.614,(95 \%$ CI, 0.547-0.678), sensitivity $52.2 \%$ and specificity $70.7 \% ; \mathrm{P}=0.003]$, and that for adjacent area was 87/HPF [AUC 0.599, (0.534-0.661), 49.5 and 70.5\%, $\mathrm{P}=0.008$ ] (Fig. 3). In contrast, the optimal cut-off value for intratumor CD206 was 25/HPF [AUC 0.527, (0.465-0.588), sensitivity $56.2 \%$, specificity $52.8 \% ; \mathrm{P}=0.463$ ] while the value for tumor-adjacent area was 83/HPF [AUC 0.534, (0.469-0.599), 44.7, 69.2\%; P=0.384] (Fig. 3).

Prognostic significance of CD206 and CD68 expression in HCC patients after operation. The prognostic value of CD68 and CD206 expression in postsurgical HCC patients was examined and data are shown in Table $\mathrm{V}$ and Fig. 4. Within a median follow-up time of 44 months (1-54 months), 5-year OS and DFS rates for the 199 patients were 47 and $62 \%$. The analyses showed that the median value for density of CD68 in intratumor was $61 / \mathrm{HPF}$ (CD68 density $\geq 61 / \mathrm{HPF}$ was defined as CD68 ${ }^{\text {high }}$ group, CD68 density $<61 / \mathrm{HPF}$ was defined as CD68 ${ }^{\text {low }}$ group) and that in adjacent area was 78/HPF (CD68 density $\geq 78 / \mathrm{HPF}$ was defined as CD $68^{\text {high }}$ group, CD68 density $<78 / \mathrm{HPF}$ was defined as $\mathrm{CD} 68^{\text {low }}$ group), respectively. Similarly, 29/HPF and 66/HPF were the medians of CD206 macrophage content for the two areas.

Survival analyses revealed that high density of CD206-positive macrophages in intratumor tissues was significantly associated with reduced $\mathrm{OS}(\mathrm{P}=0.013$; Fig. 4E) and DFS ( $\mathrm{P}=0.003$; Fig. 4F) in post-surgical HCC patients. On the contrary, we noted that increased CD68-positive macrophages were significantly correlated with better
Table IV. Difference in the density of CD68-positive and CD206-positive macrophages in tumor and adjacent tissue (mean $\pm \mathrm{SD})$.

\begin{tabular}{lccc}
\hline & \multicolumn{2}{c}{ Density } & \\
\cline { 2 - 3 } Staining & $\mathrm{n}$ & Mean \pm SD & P-value (paired t-test) \\
\hline CD68 & & & $<0.001$ \\
$\quad$ Intratumor & 216 & $66.59 \pm 32.89$ & \\
$\quad$ Adjacent & 216 & $79.41 \pm 23.42$ & \\
CD206 & & & $<0.001$ \\
$\quad$ Intratumor & 236 & $31.55 \pm 15.03$ & \\
Adjacent & 236 & $64.36 \pm 15.83$ & \\
Intratumor & & & $<0.001$ \\
CD68 & 223 & $66.61 \pm 32.89$ & \\
CD206 & 223 & $30.42 \pm 15.13$ & \\
Adjacent & & & $<0.001$ \\
$\quad$ CD68 & 220 & $79.89 \pm 22.64$ & \\
CD206 & 220 & $63.95 \pm 15.85$ & \\
\hline
\end{tabular}

survival only in tumor adjacent area $(\mathrm{P}=0.020$; Fig. $4 \mathrm{C})$ and patients with low CD68 expression in adjacent area exhibited a worse DFS ( $\mathrm{P}=0.018$; Fig. 4D). However, no significant correlations of CD68-positive macrophages infiltrated in intratumor $(\mathrm{P}=0.906$ and $\mathrm{P}=0.535$, respectively; Fig. 4A and B) and CD206-positive macrophages in adjacent compartment with prognosis $(\mathrm{P}=0.330$ and $\mathrm{P}=0.912$, respectively; Fig. $4 \mathrm{G}$ and $\mathrm{H}$ ).

Univariate analysis of prognostic factors revealed that CD68-positive macrophages in tumor adjacent tissue and CD206-positive macrophages in intratumor had significant prognostic effects on OS in post-surgical HCC patients $(\mathrm{P}=0.024$ and $\mathrm{P}=0.014$, respectively) (Table V). In addition, both low CD68 density in tumor adjacent tissue $(\mathrm{P}=0.008)$ and high $\mathrm{CD} 206$ density in intratumor $(\mathrm{P}=0.016)$ were identified as independent predictors of poor prognosis for OS by multivariate survival analysis after adjustment of covariates (Table V). Similar results were obtained for DFS. Increased CD68-positive macrophages in tumor adjacent tissue $(\mathrm{P}=0.016)$ and enhanced intratumor $\mathrm{CD} 206$-positive macrophages $(\mathrm{P}=0.003)$ played significant roles by univariate analysis. Multivariate survival analysis showed both CD68 density in tumor adjacent tissue $(\mathrm{P}=0.028)$ and $\mathrm{CD} 206$ density in intratumor tissue $(\mathrm{P}=0.005)$ could be as independent predictors for DFS (Table V).

Combination of adjacent area CD68 density with intratumoral CD206 density analysis. Patients were classified into four groups according to their intratumoral CD206 and adjacent tumoral CD68 densities (Table V): group I ( $\mathrm{n}=65)$, low CD206 and CD68 density; group II (n=39), high CD206 but low CD68 density; group III ( $\mathrm{n}=46$ ), low CD206 but high CD68 density; and group IV ( $\mathrm{n}=49)$, high CD206 and CD68 density. Differences in both OS (P=0.040; Fig. 5A) and DFS $(\mathrm{P}=0.015$; Fig. 5B) were significant among the four groups and group II had the worst survival. 

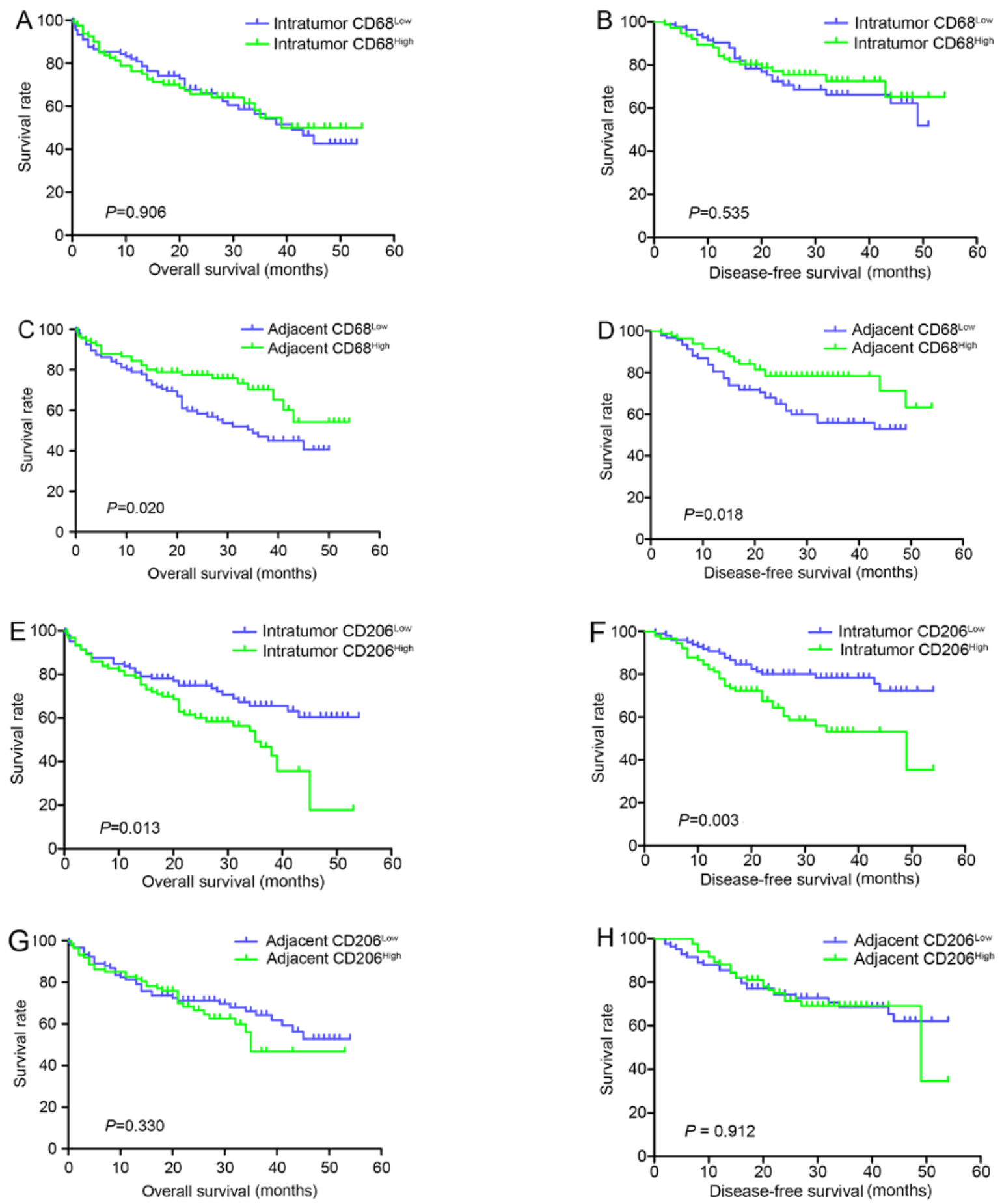

Figure 4. OS and DFS for infiltrated CD206-positive and CD68-positive macrophages in different tumor areas of post-surgical HCC patients. In HCC patients after operation, the low CD68 expression in adjacent tumor and high density of CD206-positive macrophages in intratumor tissues were significantly associated with reduced OS and DFS (C-F). However, no significant association of CD68-positive macrophages infiltrated in intratumor and CD206-positive macrophages in adjacent compartment with prognosis was found (A, B, G and $\mathrm{H})$.

Combination of adjacent area CD68 density/intratumoral $C D 206$ density with $H B V$. To assess whether the combined use of adjacent area CD68 density and HBV infective status was better than either of these biomarkers alone, four groups were assessed as follows (Table V and Fig. 6): group I ( $n=69)$, high CD68 density and positive HBV; group II $(n=27)$, high CD68 density but negative HBV; group III ( $\mathrm{n}=80)$, low CD68 density but positive HBV; and group IV ( $n=23)$, low CD68 density and negative $\mathrm{HBV}$. We found a significant difference in DFS ( $\mathrm{P}=0.001$; Fig. 6B), but not in $\mathrm{OS}(\mathrm{P}=0.102$; Fig. 6A) among the four groups. Group III with low CD68 density in adjacent tumor but positive HBV had the shortest recurrence time.

Similarly, another grouping approach is listed in Table V and Fig. 6C and D. There were significant differences in either OS ( $\mathrm{P}=0.043$; Fig. 6C) or DFS $(\mathrm{P}<0.001$; Fig. 6D) among the four groups. Of note, group I had the poorest DFS. However, in univariate analysis, only difference in DFS $(\mathrm{P}<0.001)$ is shown in Table V. In brief, the combined predictive value in DFS was much greater than that of CD68 or CD206 alone. 
Table V. Univariate and multivariate analysis of different parameters with survival and recurrence in HCC patients.

\begin{tabular}{|c|c|c|c|c|c|c|c|c|}
\hline \multirow[b]{3}{*}{ Variables } & \multicolumn{4}{|c|}{ OS } & \multicolumn{4}{|c|}{ DFS } \\
\hline & \multirow{2}{*}{$\begin{array}{l}\text { Univariate } \\
\text { P-value }\end{array}$} & \multicolumn{3}{|c|}{ Multivariate } & \multirow{2}{*}{$\begin{array}{l}\text { Univariate } \\
\mathrm{P} \text {-value }\end{array}$} & \multicolumn{3}{|c|}{ Multivariate } \\
\hline & & HR & $95 \%$ CI & P-value & & HR & $95 \% \mathrm{CI}$ & P-value \\
\hline $\begin{array}{l}\text { Alcohol intake } \\
\text { Yes vs. no }\end{array}$ & 0.257 & & & NA & 0.212 & & & NA \\
\hline $\begin{array}{l}\text { Smoking } \\
\text { Yes vs. no }\end{array}$ & 0.012 & 1.717 & $1.069-2.759$ & 0.025 & 0.866 & & & NA \\
\hline $\begin{array}{l}\text { HBV } \\
\text { Positive vs. negative }\end{array}$ & 0.212 & & & NA & 0.003 & 3.898 & $1.400-10.854$ & 0.009 \\
\hline $\begin{array}{l}\text { Liver cirrhosis } \\
\text { Present vs. absent }\end{array}$ & 0.448 & & & NA & 0.961 & & & NA \\
\hline $\begin{array}{l}\text { PHT } \\
\text { Present vs. absent }\end{array}$ & 0.436 & & & NA & 0.334 & & & NA \\
\hline $\begin{array}{l}\text { TBIL } \\
<34 \text { vs. } \geq 34\end{array}$ & 0.867 & & & NA & 0.699 & & & NA \\
\hline $\begin{array}{l}\text { Albumin } \\
<35 \text { vs. } \geq 35\end{array}$ & 0.026 & 0.360 & $0.205-0.632$ & $<0.001$ & 0.280 & & & NA \\
\hline $\begin{array}{l}\text { AFP } \\
<400 \text { vs. } \geq 400\end{array}$ & 0.438 & & & NA & 0.206 & & & NA \\
\hline $\begin{array}{l}\text { Child-Pugh class } \\
\text { A vs. B vs. C }\end{array}$ & 0.740 & & & NA & 0.865 & & & NA \\
\hline $\begin{array}{l}\text { Tumor size } \\
<5 \text { vs. } \geq 5\end{array}$ & 0.311 & & & NA & 0.936 & & & NA \\
\hline $\begin{array}{l}\text { Lymph node metastasis } \\
\text { Present vs. absent }\end{array}$ & $<0.001$ & 8.238 & $3.126-21.710$ & $<0.001$ & 0.460 & & & NA \\
\hline Primary lesion & $<0.001$ & 1.531 & $1.295-1.811$ & $<0.001$ & 0.054 & 1.214 & $1.001-1.473$ & 0.049 \\
\hline $\begin{array}{l}\text { TNM stage: } \\
\text { I + I vs. III + IV }\end{array}$ & $<0.001$ & 2.052 & $1.637-2.571$ & $<0.001$ & 0.326 & & & NA \\
\hline $\begin{array}{l}\text { Tumor differentiation } \\
\text { Well vs. moderate vs. poor }\end{array}$ & 0.421 & & & NA & 0.206 & & & NA \\
\hline $\begin{array}{l}\text { Intratumor features } \\
\text { Low vs. high }\end{array}$ & & & & NA & & & & NA \\
\hline CD68 density & 0.907 & & & & 0.538 & & & \\
\hline CD206 density & 0.014 & 1.792 & $1.116-2.879$ & 0.016 & 0.003 & 2.222 & $1.280-3.856$ & 0.005 \\
\hline $\begin{array}{l}\text { Adjacent tumor features } \\
\text { Low vs. high }\end{array}$ & & & & & & & & \\
\hline CD68 density & 0.024 & 0.510 & $0.311-0.837$ & 0.008 & 0.016 & 0.529 & $0.299-0.935$ & 0.028 \\
\hline CD206 density & 0.334 & & & NA & 0.912 & & & NA \\
\hline $\begin{array}{l}\text { Combine adjacent tumoral } \\
\text { CD68 and intratumoral CD206 }\end{array}$ & 0.040 & & & NA & 0.015 & & & NA \\
\hline $\begin{array}{l}\text { Combine adjacent tumoral } \\
\text { CD68 and HBV }\end{array}$ & 0.014 & & & NA & 0.326 & & & NA \\
\hline Combine intratumoral CD206 and HBV & 0.070 & & & NA & $<0.001$ & & & NA \\
\hline
\end{tabular}

OS, overall survival; DFS, disease-free survival; NA, not adopted; HBV, hepatitis B virus; PHT, portal hypertension; TBIL, total bilirubin; AFP, alpha-fetoprotein; TNM, tumor-node-metastasis; HR, hazard ratio; CI, confidence interval. 

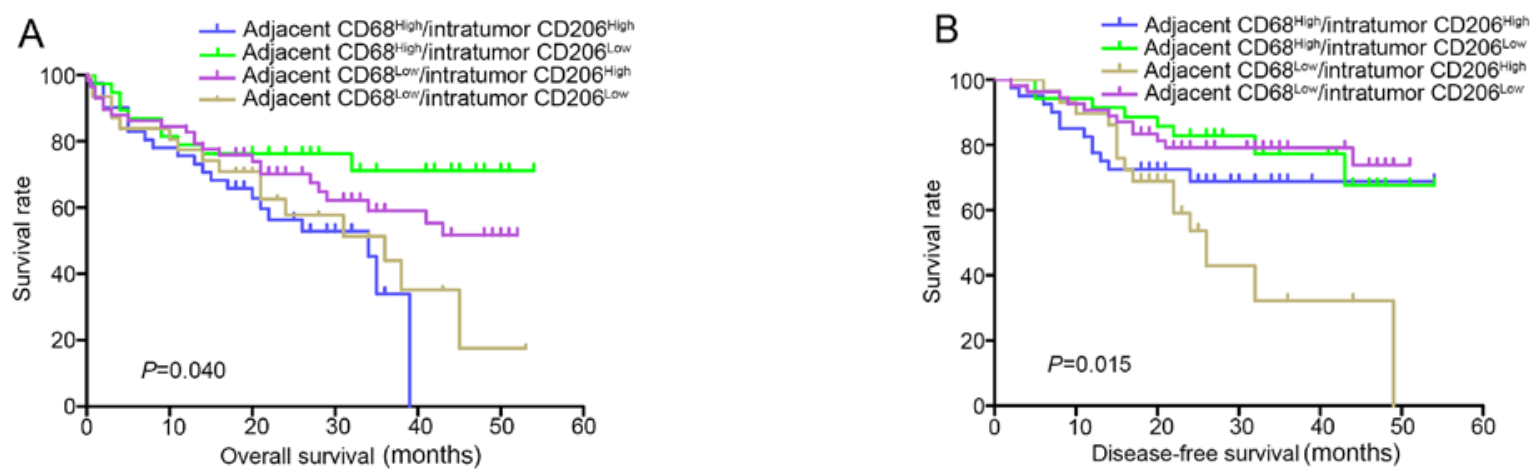

Figure 5. OS and DFS for combination of adjacent tumoral CD68 density with intratumoral CD206 density. Combined analysis of adjacent tumoral CD68 with intratumoral CD206, differences in both OS (A) and DFS (B) were significant.
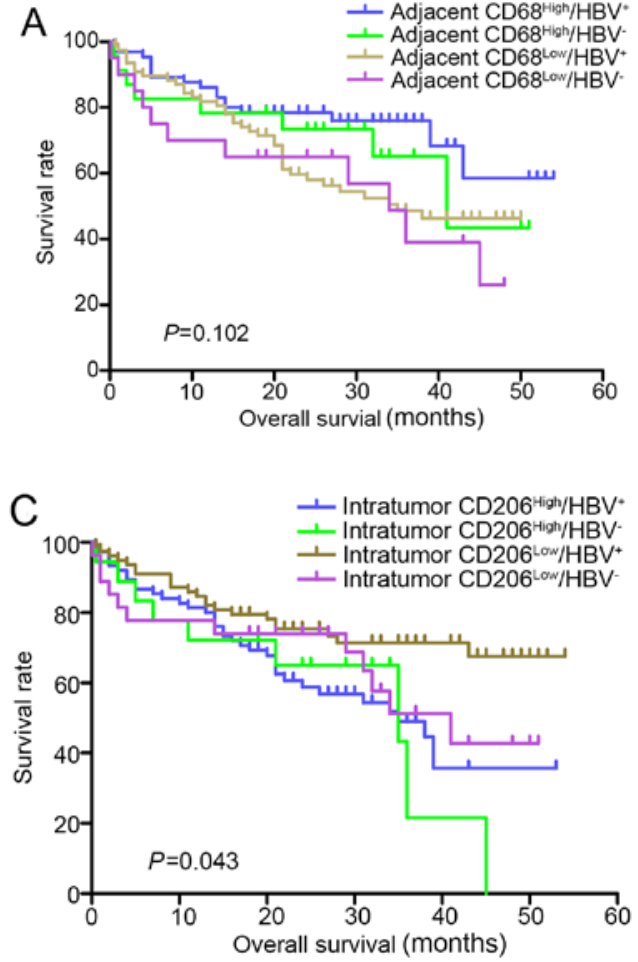
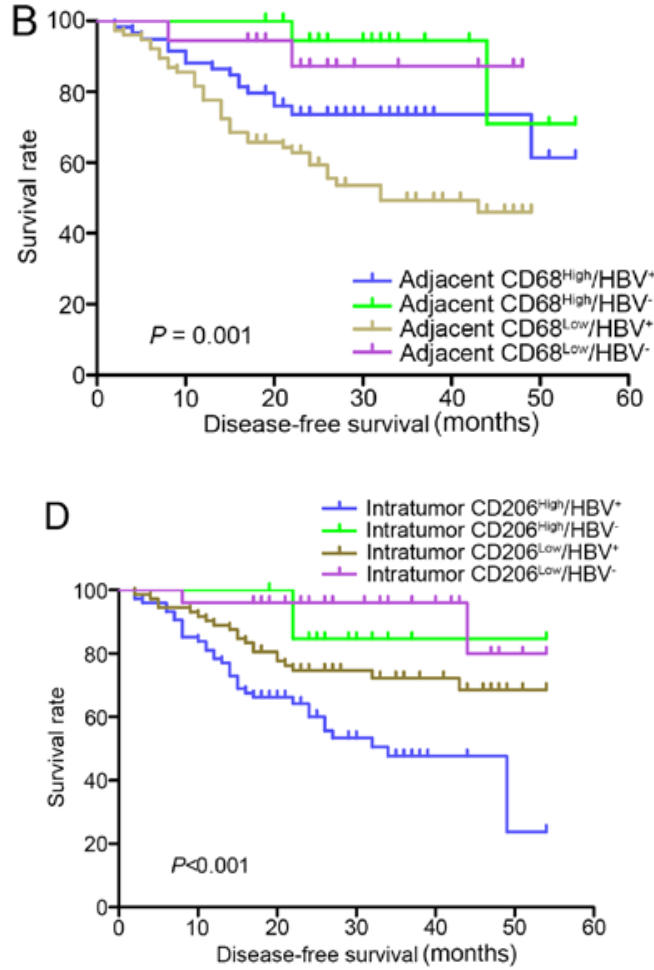

Figure 6. OS and DFS for combination of adjacent tumoral CD68 density/intratumoral CD206 density with HBV. Combination of either adjacent CD68 or intratumoral CD206 with HBV, was significantly different in DFS (B and D). There was significant difference in OS for the combination of intratumoral CD206 with HBV (C), but not for combination of either adjacent CD68 or HBV (A).

\section{Discussion}

Results from the present study demonstrate that changes to CD68-positive and CD206-positive macrophage subpopulations in tumor site and adjacent region in HCC are associated with OS and DFS. To the best of our knowledge, this is the first study that shows location-specific and subtype-specific macrophage expression and their prognostic values in HCC.

In the present study, the infiltrating CD68- and CD206positive subpopulations were observed in cancer tissues and in adjacent tissues of HCC, with predominant presence in the adjacent tumor tissues. CD68-positive macrophages were much more abundant than CD206-positive macrophages both in the intratumor and adjacent areas. This is in accordance with the fact that the total number of CD68-positive macrophages is greater than that of CD206-positive M2 macrophages. According to the infiltrating macrophage count, there was a notable increase of CD68 expression in non-tumor tissues in line with the increased macrophage expression and inflammatory response in HCC demonstrated previously by others $(25,26)$. This result is in contrast to several investigations which showed overexpression of CD68 in tumor tissue (27). This suggests the expression profile of CD68 in tumor and adjacent tumor-free region is specific to HCC. The increased number of CD68-positive macrophages in HCC adjacent samples in our analysis may be explained by heterogeneity of macrophages in response to different microenvironment signals. Thus, the subtype of CD68-positive macrophages in adjacent tissue is probably different from that in intratumor tissue and they may represent resident macrophages (CD68-positive Kupffer 
cells). Specifically, CD68-positive macrophages in adjacent tumor are more similar to macrophages in normal or inflamed tissues that possess spontaneous antitumor activity. Therefore, these cells would be beneficial in the prognosis of HCC (28). These data suggest a possibility that as a front line defense to prevent tumor growth, the adjacent non-tumor liver tissue is endowed with abundant CD68-positive macrophages. Positive correlation of increased amount of adjacent CD68-positive macrophages with good HCC prognosis in the present study could be explained by the ability of macrophages that are not yet re-programmed by tumor cells to kill cancer cells. In other words, CD68-positive macrophages in adjacent tissue may have antitumor activity as they are uneducated into M2 phenotype by cancer, while in tumor the opposite happens. In tumor area, a genetic exchange between the primary tumor cells and the associated macrophages may lead to the expression of a more invasive phenotype of macrophages. On the other hand, immunohistochemistry with antibodies to CD206 also identified a higher CD206 density in adjacent tissue in HCC patients, which is similar to a study examining the higher proliferation of endothelial cells to IL-6/sIL-6R in HCC peritumor (29). Generally, CD206 can identify mannose and fucose glycoconjugates and has been recognized as an important regulator in the phagocytosis of intracellular pathogens. Herein we speculate that this phagocytosis in tumor may consume a large number of CD206 so that the count of CD206 would be reduced dramatically in intratumor. However, the mechanism for overexpression of CD68 and higher density of CD206 in the adjacent liver tissue remains unclear. One possible mechanism is tumor cell-micro environmental crosstalk which is complex. Another possibility is that a line of defense surrounding tumor formed by tumor microenvironment may block the entrance of macrophages into the tumor. Furthermore, the tumor itself could be a possible stimulator either stimulating chronic inflammation or causing a host hepatocyte reaction (26), resulting in elevated production of cytokines and more CD68/CD206 at the tumor-host margin. Moreover, the heterogeneity of macrophages in HCC raises a further possibility that there are different distributions and phenotypes of macrophages in different tumor parts and nearby areas. We propose that some genetic heterogeneity among different individuals may lead to the different baseline expression level of CD68/CD206. In this regard, previous evidence concerning the density of TAMs in HCC partly contrasts with our data. These discrepancies could be due to differences in the methodology, sample types, or patient characteristics. Two recent studies showed no association of CD68-positive macrophages in tumor region with clinicopathological characteristics in HCC but the tumor-adjacent region was not examined $(30,31)$. Additionally, associations between CD68-positive and CD206-positive macrophages in both tumor and adjacent tissues were also found in this study. A similar relationship between CD68-positive and CD163-positive macrophages in HCC was also previously reported (21). This may suggest a possible interaction between macrophage subpopulations.

In the present study, low CD68 expression in tumor was associated with age and PHT, which could partly explain the protective role of CD68 in this study. On the contrary, patients with cirrhosis, poor TNM stages and Child-Pugh class tended to have high CD206 density, indicating the M2 role of
CD206 in cancers. On the whole, a lower correlation between CD68-positive/CD206-positive macrophages and clinicopathological characteristics in HCC patients may imply some other genetic heterogeneity within different individuals. Our results also suggest that CD68 expression either in intratumor or in adjacent tumor may be a potential diagnostic measure of HCC. However, the effectiveness of this emerging marker requires further assessment.

Prognostic factors are of paramount interest in the risk assessment of cancer patients. This study demonstrated that the dense CD68 infiltration in the tumor adjacent tissues, but not in primary tumor tissues, was strongly associated with favorable survival of both OS and DFS for post-operative HCC patients in univariate and multivariate analyses. This is consistent with another report on esophageal squamous cell carcinoma (32). However, CD68 has been frequently shown to correlate with an adverse prognosis in a variety of malignancies, such as oral squamous cell carcinoma and HCC (21-24). Recently, dual prognostic significance of CD68-positive TAMs has been reported in pancreatic ductal adenocarcinoma (PDAC) (33). In this study, CD68-TAMs at the tumor-stroma interface may promote PDAC distant metastasis, while in patients who have received chemotherapy, TAMs play an opposite role. Additionally, some authors suggested that CD68-positive macrophages did not affect the outcome of patients with classical Hodgkin lymphoma (34). A similar finding was reported recently by Shu et al (30), however, we thought that the results could not comprehensively and accurately reveal the prognostic value of CD68 as they only analyzed HCC tissues for CD68-positive macrophages rather than adjacent tissues.

Macrophages in normal or inflamed tissues possess spontaneous antitumor activity, while TAMs seem to have distinct phenotypes with diverse functional programs within different local environment (28). This might suggest that CD68-positive macrophages, exhibiting M1-like phenotype, serve as a protective phenotype and likely lessen HCC damage. Moreover, TAMs in HCC are heterogeneous and present different phenotypes as heterogeneity and plasticity are hallmarks of macrophages (22). Possibly, there was different depletion or recruitment of heterogeneous populations of protumor and antitumor macrophages in the liver. Also, plasticity of macrophages allowed them to acquire either protumor or antitumor functions (35). Thus, it was not surprising to find various functional phenotypes of macrophages in adjacent tissue versus intratumor tissue, as seen in the present study. Positive correlation of increased amount of adjacent CD68-positive macrophages with HCC prognosis in this study could be due to the macrophages that were not yet re-programmed into M2 phenotype by tumor cells and still possessed the ability of killing cancer cells.

In our HCC patient cohort, the increased CD206-positive M2 macrophages at primary tumor tissues were correlated with poor prognosis. The bulk of available information indicates that CD206-positive M2 macrophages appear to possess mostly tumor promoting property $(36,37)$. This is in line with a poor prognosis and hence the prognostic value of intratumor CD206 macrophages in HCC patients. Although intratumoral CD206-positive M2-macrophages were reported to promote tumor cell dissemination, the adjacent CD206-positive macrophages may play a different, even opposite role. Herein, 
intratumoral CD206-positive macrophages contributed to a propensity of metastases and poor prognosis for HCC. Our results strongly demonstrate that intratumoral CD206 is an independent factor of prognosis for postsurgical HCC patients. In contrast, another study reported an association of decreased CD206-positive macrophages with loss of interstitial cells of Cajal in patients with diabetic gastroparesis, indicating a cytoprotective role for CD206-positive macrophages (38). These data may prompt a therapeutic strategy that targets intratumoral CD206 by reprogramming its protumor phenotype into an effective antitumor activity. Our findings with CD206-positive macrophages are consistent with two recent reports that CD206 in tumor region of $\mathrm{HCC}$ was linked to poor prognosis. However, by examining CD68/CD206-positive macrophages in both tumor tissues and adjacent tissues, our models have higher predicative power.

Furthermore, we found a much greater advantage in combining capability of intratumor CD206 with adjacent CD68 in prognostic prediction of HCC. There are greater numbers of younger patients with HBV-related HCC in Asian countries including China (39), as shown in the present study (Table I). The findings revealed a better prognostic value, especially in recurrence. According to the Cox regression model that included the levels of CD68/CD206-positive macrophage content, smoking, HBV, albumin, lymph node metastasis, primary lesion and TNM, it was concluded that primary lesion, adjacent CD68 and intratumor CD206 were independent prognostic factors for both OS and DFS.

In conclusion, this study clearly demonstrates higher densities of CD68 and CD206 in the adjacent liver tissue than those in tumor tissue. The dense CD206 macrophage infiltration at the tumor is an independent predictor of poor survival in postsurgical HCC patients. High density of CD68 macrophage infiltration in adjacent tissue is capable of predicting improved survival. The findings from this study suggest the complexity of macrophages within and surrounding tumor microenvironment, a novel role for CD68/CD206-positive macrophages and a basis for targeting these cells as new therapeutic strategies for HCC patients.

\section{Acknowledgements}

The present study was supported by the Chinese National High Level Personnel Special Support Plan. C.W. gratefully acknowledges support from Biotechnology and Biological Sciences Research Council (BBSRC) (BB/P004695/1).

\section{References}

1. van den Bosch MA and Defreyne L: Hepatocellular carcinoma Lancet 380: 469-470; author reply 470-461, 2012.

2. Steeg PS: Tumor metastasis: Mechanistic insights and clinical challenges. Nat Med 12: 895-904, 2006.

3. Mosser DM and Edwards JP: Exploring the full spectrum of macrophage activation. Nat Rev Immunol 8: 958-969, 2008.

4. Pollard JW: Tumour-educated macrophages promote tumour progression and metastasis. Nat Rev Cancer 4: 71-78, 2004.

5. Fridman WH, Pagès F, Sautès-Fridman C and Galon J: The immune contexture in human tumours: Impact on clinical outcome. Nat Rev Cancer 12: 298-306, 2012.

6. Balkwill F and Mantovani A: Inflammation and cancer: Back to Virchow? Lancet 357: 539-545, 2001.

7. Noy R and Pollard JW: Tumor-associated macrophages: From mechanisms to therapy. Immunity 41: 49-61, 2014.
8. Qian BZ and Pollard JW: Macrophage diversity enhances tumor progression and metastasis. Cell 141: 39-51, 2010.

9. Sica A, Larghi P, Mancino A, Rubino L, Porta C, Totaro MG, Rimoldi M, Biswas SK, Allavena $\mathrm{P}$ and Mantovani A: Macrophage polarization in tumour progression. Semin Cancer Biol 18: 349-355, 2008.

10. Atanasov G, Hau HM, Dietel C, Benzing C, Krenzien F, Brandl A, Wiltberger G, Matia I, Prager I, Schierle K, et al: Prognostic significance of macrophage invasion in hilar cholangiocarcinoma. BMC Cancer 15: 790, 2015.

11. Lawrence $T$ and Natoli G: Transcriptional regulation of macrophage polarization: Enabling diversity with identity. Nat Rev Immunol 11: 750-761, 2011.

12. Mantovani A, Allavena P, Sica A and Balkwill F: Cancer-related inflammation. Nature 454: 436-444, 2008.

13. Welsh TJ, Green RH, Richardson D, Waller DA, O'Byrne KJ and Bradding P: Macrophage and mast-cell invasion of tumor cell islets confers a marked survival advantage in non-small-cell lung cancer. J Clin Oncol 23: 8959-8967, 2005.

14. Hutterer GC, Pichler M, Chromecki TF, Strini KA, Klatte T, Pummer K, Remzi M, Mannweiler S and Zigeuner R: Tumour-associated macrophages might represent a favourable prognostic indicator in patients with papillary renal cell carcinoma. Histopathology 63: 309-315, 2013.

15. Falini B, Flenghi L, Pileri S, Gambacorta M, Bigerna B, Durkop H, Eitelbach F, Thiele J, Pacini R, Cavaliere A, et al: PG-M1: A new monoclonal antibody directed against a fixativeresistant epitope on the macrophage-restricted form of the CD68 molecule. Am J Pathol 142: 1359-1372, 1993.

16. Huang $\mathrm{H}$, Chen A, Wang T, Wang M, Ning X, He M, Hu Y, Yuan L, Li S, Wang Q, et al: Detecting cell-in-cell structures in human tumor samples by E-cadherin/CD68/CD45 triple staining. Oncotarget 6: 20278-20287, 2015.

17. Gordon S: Alternative activation of macrophages. Nat Rev Immunol 3: 23-35, 2003.

18. Gazi U and Martinez-Pomares L: Influence of the mannose receptor in host immune responses. Immunobiology 214: 554-561, 2009.

19. Medrek C, Pontén F, Jirström K and Leandersson K: The presence of tumor associated macrophages in tumor stroma as a prognostic marker for breast cancer patients. BMC Cancer 12: 306, 2012.

20. Zhu F, Li X, Jiang Y, Zhu H, Zhang H, Zhang C, Zhao Y and Luo F: GdCl3 suppresses the malignant potential of hepatocellular carcinoma by inhibiting the expression of CD206 in tumor-associated macrophages. Oncol Rep 34: 2643-2655, 2015.

21. Kong LQ, Zhu XD, Xu HX, Zhang JB, Lu L, Wang WQ, Zhang QB, Wu WZ, Wang L, Fan J, et al: The clinical significance of the $\mathrm{CD}_{163^{+}}$and $\mathrm{CD} 68^{+}$macrophages in patients with hepatocellular carcinoma. PLoS One 8: e59771, 2013.

22. Wang H, Wang X, Li X, Fan Y, Li G, Guo C, Zhu F, Zhang L and Shi Y: CD68 ${ }^{+} \mathrm{HLA}-\mathrm{DR}^{+}$M1-like macrophages promote motility of HCC cells via NF-кB/FAK pathway. Cancer Lett 345: 91-99, 2014.

23. Ni YH, Ding L, Huang XF, Dong YC, Hu QG and Hou YY: Microlocalization of CD68 tumor-associated macrophages in tumor stroma correlated with poor clinical outcomes in oral squamous cell carcinoma patients. Tumour Biol 36: 5291-5298, 2015.

24. Hu Y, He MY, Zhu LF, Yang CC, Zhou ML, Wang Q, Zhang W, Zheng YY, Wang DM, Xu ZQ et al: Tumor-associated macrophages correlate with the clinicopathological features and poor outcomes via inducing epithelial to mesenchymal transition in oral squamous cell carcinoma. J Exp Clin Cancer Res 35: 12, 2016.

25. Cervello M, Foderàa D, Florena AM, Soresi M, Tripodo C, D'Alessandro N and Montalto G: Correlation between expression of cyclooxygenase-2 and the presence of inflammatory cells in human primary hepatocellular carcinoma: Possible role in tumor promotion and angiogenesis. World J Gastroenterol 11: 4638-4643, 2005.

26. Zhu XD, Zhang JB, Zhuang PY, Zhu HG, Zhang W, Xiong YQ, Wu WZ, Wang L, Tang ZY and Sun HC: High expression of macrophage colony-stimulating factor in peritumoral liver tissue is associated with poor survival after curative resection of hepatocellular carcinoma. J Clin Oncol 26: 2707-2716, 2008.

27. Jensen TO, Schmidt H, Møller HJ, Høyer M, Maniecki MB, Sjoegren P, Christensen IJ and Steiniche T: Macrophage markers in serum and tumor have prognostic impact in American Joint Committee on Cancer stage I/II melanoma. J Clin Oncol 27: 3330-3337, 2009. 
28. Murdoch C, Giannoudis A and Lewis CE: Mechanisms regulating the recruitment of macrophages into hypoxic areas of tumors and other ischemic tissues. Blood 104: 2224-2234, 2004

29. Zhuang PY, Wang JD, Tang ZH, Zhou XP, Quan ZW, Liu YB and Shen J: Higher proliferation of peritumoral endothelial cells to IL-6/sIL-6R than tumoral endothelial cells in hepatocellular carcinoma. BMC Cancer 15: 830, 2015.

30. Shu QH, Ge YS, Ma HX, Gao XQ, Pan JJ, Liu D, Xu GL, Ma JL and Jia WD: Prognostic value of polarized macrophages in patients with hepatocellular carcinoma after curative resection. J Cell Mol Med 20: 1024-1035, 2016.

31. Dong P, Ma L, Liu L, Zhao G, Zhang S, Dong L, Xue R and Chen S: $\mathrm{CD}^{2} 6^{+} / \mathrm{CD} 206^{+}$, diametrically polarized tumor-Associated macrophages, predict hepatocellular carcinoma patient prognosis. Int J Mol Sci 17: 320, 2016

32. Li J, Zhang BZ, Qin YR, Bi J, Liu HB, Li Y, Cai MY, Ma S, Chan KW, Xie D, et al: CD68 and interleukin 13, prospective immune markers for esophageal squamous cell carcinoma prognosis prediction. Oncotarget 7: 15525-15538, 2016.

33. Di Caro G, Cortese N, Castino GF, Grizzi F, Gavazzi F Ridolfi C, Capretti G, Mineri R, Todoric J, Zerbi A, et al: Dual prognostic significance of tumour-associated macrophages in human pancreatic adenocarcinoma treated or untreated with chemotherapy. Gut 65: 1710-1720, 2015.
34. Klein JL, Nguyen TT, Bien-Willner GA, Chen L, Foyil KV, Bartlett NL, Duncavage EJ, Hassan A, Frater JL and Kreisel F: CD163 immunohistochemistry is superior to CD68 in predicting outcome in classical Hodgkin lymphoma. Am J Clin Pathol 141: 381-387, 2014.

35. Sica A and Mantovani A: Macrophage plasticity and polarization: In vivo veritas. J Clin Invest 122: 787-795, 2012.

36. Benson DD, Meng X, Fullerton DA, Moore EE, Lee JH, Ao L, Silliman CC and Barnett CC Jr: Activation state of stromal inflammatory cells in murine metastatic pancreatic adenocarcinoma. Am J Physiol Regul Integr Comp Physiol 302: R1067-R1075, 2012.

37. Karnevi E, Andersson R and Rosendahl AH: Tumour-educated macrophages display a mixed polarisation and enhance pancreatic cancer cell invasion. Immunol Cell Biol 92: 543-552, 2014.

38. Bernard CE, Gibbons SJ, Mann IS, Froschauer L, Parkman HP, Harbison S, Abell TL, Snape WJ, Hasler WL, McCallum RW, et al: Association of low numbers of CD206-positive cells with loss of ICC in the gastric body of patients with diabetic gastroparesis. Neurogastroenterol Motil 26: 1275-1284, 2014.

39. El-Serag HB: Hepatocellular carcinoma. N Engl J Med 365: 1118-1127, 2011. 